\title{
Inspeção predial em edificações de Capão da Canoa - Elaboração de laudo técnico de inspeção predial (LTIP)
}

\author{
D. S. Pinto. ${ }^{1}$, G. C. Menegussi ${ }^{2 *}$ \\ *Autor de Contato: giovanna_menegussi@hotmail.com \\ ${ }^{1}$ Pós-graduando em Engenharia Civil, Universidade do Vale do Rio dos Sinos, São Leopoldo, Brasil. \\ ${ }^{2}$ Graduanda em Engenharia Civil, Universidade do Vale do Rio dos Sinos, São Leopoldo, Brasil.
}

\begin{abstract}
RESUMO
O concreto armado é um dos materiais de maior empregabilidade na construção civil, dada sua facilidade de moldagem, baixo custo, bom desempenho mecânico, entre outros fatores. Porém, quando se encontra em localidades próximas da orla marinha, pode apresentar corrosão nas armaduras, visto que, nesses locais, normalmente há alta concentração de sais e umidade, que servem de gatilhos para esse fenômeno. Destarte, tem-se a inspeção dessas estruturas como de suma importância para que se efetue as manutenções necessárias e, se for o caso, até mesmo reforços. A falta da referida manutenção ou a sua má execução pode culminar no colapso de edificações em regiões litorâneas, como do edifício Andréa - na cidade de Fortaleza, CE - e, no Rio Grande do Sul, o edifício Santa Fé, localizado na Beira-Mar de Capão da Canoa. Após esse último episódio, Capão da Canoa conta com a lei municipal de $n^{\circ} 2.678$, de 24 de dezembro de 2009, que estabelece a obrigatoriedade de inspeção em todas edificações verticais do município. Assim sendo, tendo em vista esse cenário, esse trabalho objetivou a Inspeção em edificações de Capão da Canoa, identificando danos patológicos em edificações de região litorânea, buscando suas origens e intervenções cabíveis.
\end{abstract}

Palavras chave: inspeção; manifestações patológicas; manutenção.

\begin{abstract}
Reinforced concrete is one of the most used materials in civil construction, due to the facility of molding, low cost, good mechanical performance, among ohter factors. However, when it is located
\end{abstract}


in places close to the sea, it may show corrosion in the armor, since in these places there is usually a high concentration of salts and moisture, which serve as triggers for this phenomenon. Thus, the inspection of these structures is of paramount importance in order to carry out the necessary maintenance and, if necessary, even reinforcements. The lack of such maintenance or its poor execution can culminate in the collapse of buildings in coastal regions, such as the Andréa building - in the city of Fortaleza, CE - and, in Rio Grande do Sul, the Santa Fé building, located in sea shore of Capão da Canoa. After this last episode, Capão da Canoa has the municipal law No. 2,678, of December 24, 2009, which establishes the mandatory inspection of all vertical buildings in the municipality. Therefore, in view of this scenario, this work aimed at the Inspection of buildings in Capão da Canoa, identifying pathological damages in buildings in the coastal region, seeking their origins and appropriate interventions.

Keywords: inspection; pathological manifestations; maintenance.

\section{RESUMEN}

El hormigón armado es uno de los materiales más empleables en la construcción civil, dada su facilidad de moldeo, bajo costo, buen desempeño mecánico, entre otros factores. Sin embargo, cuando se ubica en lugares cercanos a la orilla del mar, puede presentar corrosión en el blindaje, ya que en estos lugares suele haber una alta concentración de sales y humedad, que sirven como detonantes de este fenómeno. Por tanto, la inspección de estas estructuras es de suma importancia para poder realizar el mantenimiento necesario y, en su caso, incluso los refuerzos. La falta de dicho mantenimiento o su mala ejecución puede culminar en el derrumbe de edificios en regiones costeras, como el edificio Andréa - en la ciudad de Fortaleza, CE - y, en Rio Grande do Sul, el edificio Santa Fé, ubicado en la orilla del mar de Capão da Canoa. Después de este último episodio, Capão da Canoa cuenta con la ley municipal $N^{\circ} 2.678$, del 24 de diciembre de 2009, que establece la inspección obligatoria de todos los edificios verticales del municipio. Por lo tanto, ante este escenario, este trabajo tuvo como objetivo la Inspección de edificios en Capão da Canoa, identificando daños patológicos en edificios en la región costera, buscando sus orígenes e intervenciones adecuadas.

Palabras clave: inspección; manifestaciones patológicas; mantenimiento.

\section{INTRODUÇÃO}

O concreto é o material de construção mais utilizado mundialmente e pode ser encontrado nos mais diversos tipos de obra, desde casas de alvenaria até nos edifícios mais altos do planeta. Anualmente, estima-se que 11 bilhões de toneladas de concreto são utilizadas no mundo, o que representa um consumo de 1,9 toneladas por pessoa ao ano, de acordo com a Federación Iberoamericana de Hormigón Presmesclado (FIHP), quantitativo menor, apenas, do que o uso de água. Em termos de Brasil, em 2009, o consumo girou em torno de 30 milhões de metros cúbicos por ano (Pedroso, 2009). Um dado mais recente indica a produção de 12 bilhões de metros cúbicos anualmente (Sangadji, 2017).

Fatores como umidade, temperatura, concentração de agentes nocivos, pressão atmosférica e umidade influenciam na classe de agressividade do ambiente, especificação apresentada pela NBR 6118 - Projeto de estruturas de concreto - Procedimento da Associação Brasileira de Normas Técnicas (ABNT) (2014), que corresponde à classificação do meio em função da hostilidade que este impõe às estruturas. Conforme a referida norma, construções localizadas em área marinha estão inseridas em zona de agressividade forte (Pacheco 2016), que apresenta alto risco de deterioração às edificações. 
Cánovas (1988) expõe que quando uma estrutura localiza-se próxima ao mar, devido à grande concentração de sais e umidade relativa, que normalmente é alta, o ar penetra pelos vazios do concreto, danificando-o. $\mathrm{O}$ autor ainda comenta que, em algumas ocasiões, esse ambiente deletério pode atingir distâncias de $5 \mathrm{~km}$, dado que, consoante Alves (2007), Mehta e Monteiro (2014), Ribeiro et al. (2018), o vento tem potencial de transportar as partículas salinas por grandes distâncias. Helene (1986) complementa que a intensa agressividade imposta pelo meio marinho deve-se à presença de substâncias como sulfatos, cloreto de sódio e de magnésio, que contribuem para a corrosão das armaduras e degradação do concreto.

Considerando a abordagem apresentada, em virtude da grande utilização do concreto na região litorânea do Rio Grande do Sul - assim como em todo o Brasil - e em virtude da forte agressividade que esse meio apresenta às estruturas, ressalta-se a importância das rotinas de inspeção nas edificações. De acordo com Goebel (2018), é relevante a adoção de planos de inspeção, manutenção e análise das construções, de forma que, se necessário, sejam elaboradas propostas para conservar ou até mesmo aumentar a vida útil das estruturas.

Em Capão da Canoa, município do Rio Grande do Sul, no ano de 2009, um edifício de quatro pavimentos entrou em colapso enquanto passava por reforma. Apurou-se que a obra estava sendo realizada sem acompanhamento técnico, de modo que a edificação não havia sido inspecionada tecnicamente. Recentemente, um caso semelhante ocorreu na cidade de Fortaleza, no estado do Ceará, e, nessa situação, assim como no caso gaúcho, a edificação se localizava em região litorânea e desabou durante a reforma.

Após o ocorrido, o então prefeito da cidade de Capão da Canoa, Amauri Maganus Germano, sancionou a lei municipal $\mathrm{n}^{\circ} 2.678$, de 24 de dezembro de 2009, que estabelece a obrigatoriedade de realização de vistorias periódicas em edificações construídas no município. Na referida lei, estipulou-se que toda edificação vertical, após seis anos da sua execução, deve ser inspecionada e, caso seja necessário, as devidas manutenções devem ser realizadas.

Em reportagem ao portal clicrbs, no dia 20 de julho de 2009, o empreiteiro responsável pela reforma da edificação retratou: "Quando peguei o serviço para fazer, notei que parte do concreto se esfarelava ao toque, ai vi que era grave e sugeri chamar um engenheiro". Assim, pode-se concluir que a edificação não passou nem por inspeção, nem por manutenção preventiva.

O Instituto Brasileiro de Avaliações e Perícias de Engenharia (IBAPE) apresenta a Norma de Inspeção Predial Nacional, que define a inspeção predial como um levantamento, realizado individual ou em conjunto, das condições técnicas, da utilização e da manutenção da construção. Considerando o cenário apresentado, esse estudo buscou a análise de edificações localizadas em zona de agressividade forte, analisando seus danos patológicos, bem como sua ocorrência e gravidade.

\section{FUNDAMENTAÇÃO TEÓRICA}

\subsection{Agressividade}

A norma de concreto armado NBR 6118 (ABNT, 2014) identifica as classes de agressividade do meio, de acordo com o ambiente em que estão inseridas, e que devem ser consideradas na fase de projeto. A norma ainda permite um maior rigor ao projetista estrutural, que pode adotar uma classe mais agressiva, desde que tenha o devido conhecimento dos dados ambientais do local em que a estrutura será construída. As classes apresentadas pela norma estão expostas na Tabela 1. 
Tabela 1. Tabela de agressividade ambiental.

\begin{tabular}{|c|c|c|c|}
\hline $\begin{array}{c}\text { Classe de } \\
\text { agressividade } \\
\text { ambiental }\end{array}$ & Agressividade & $\begin{array}{c}\text { Classificação geral do tipo de } \\
\text { ambiente para efeito de projeto }\end{array}$ & $\begin{array}{c}\text { Risco de } \\
\text { deterioração da } \\
\text { estrutura }\end{array}$ \\
\hline I & Fraca & Rural Submersa & Insignificante \\
\hline II & Moderada & Urbana e Marinha & Pequeno \\
\hline III & Forte & Industrial e Industrial & Grande \\
\hline IV & Muito Forte & Respingos de maré & Elevado \\
\hline
\end{tabular}

Fonte: Adaptado da ABNT NBR 6118 (2014, p. 17).

Além dessas classes de agressividade impostas pela norma técnica, estudos estão sendo realizados a fim de classificar os locais em que as estruturas de concreto estão inseridas, de acordo com as peculiaridades de cada zona, como a concentração da névoa salina, o teor de umidade e a poluição do ar (Albuquerque; Otoch, 2005; Medeiros et al., 2013; Vilasboas; Machado 2010 apud Pacheco 2016).

Lima (2011) disserta que os agentes químicos, físicos e biológicos presentes na atmosfera marinha são responsáveis por uma significativa redução no desempenho e, consequentemente, na vida útil do concreto. A autora ainda explica que, nesses ambientes, mesmo que as estruturas não estejam em contato direto com a água do mar, ocorre um depósito considerável de sais em suas superfícies, em virtude da ação do vento. Em conformidade, Mehta e Monteiro (2014) expõe que a deterioração do concreto em meio marinho deve-se a ações concomitantes de processos físicos e químicos que o tornam, também, mais passível a outros tipos de ataques agressivos.

\subsection{Deterioração}

Dentre os fatores de envelhecimento patológico do concreto, a NBR 6118 (ABNT, 2014) menciona o processo de lixiviação, a expansão por sulfatos e a reação álcali-agregado. Já para a deterioração das armaduras, a norma regulamentadora traz a despassivação por carbonatação e pela ação de cloretos e, no tocante à agressividade ambiental, o desgaste do concreto relaciona-se às ações físicas e químicas atuantes na estrutura. Em adição às substâncias agressivas como gás carbônico, cloretos e sulfatos, Rebmann (2011) aponta a água como um dos principais agentes de degradação do concreto, que pode atuar como solvente e como componente de reações químicas, além de contribuir no transporte de elementos nocivos.

Outro material de grande relevância no tangente à deterioração das estruturas é a alvenaria que, assim como o concreto, está presente em grande parte das construções. Silva (2002) aponta quatro causas de manifestações patológicas em alvenarias, são elas: humanas, ações naturais, desastres naturais e desastres de causas humanas. Outrossim, o autor coloca que, partindo de uma perspectiva global, as manifestações patológicas de uma construção justificam-se por razões conjunturais ou políticas, podendo ser chamadas de "patologias precoces", isto é, aquelas manifestações patológicas que aparecem sem explicação, em pouco tempo depois da conclusão da obra.

\subsection{Manutenção}

Cánovas (1988) apresenta um esquema, representado na Figura 1, que indica como deve ser realizado o processo patológico - desde a detecção da enfermidade até o seu tratamento - a fim de, possivelmente, solucionar a manifestação patológica e retomar a capacidade de resistência da estrutura. 
Figura 1. Esquema sobre o caminho a ser seguido em todo processo patológico.

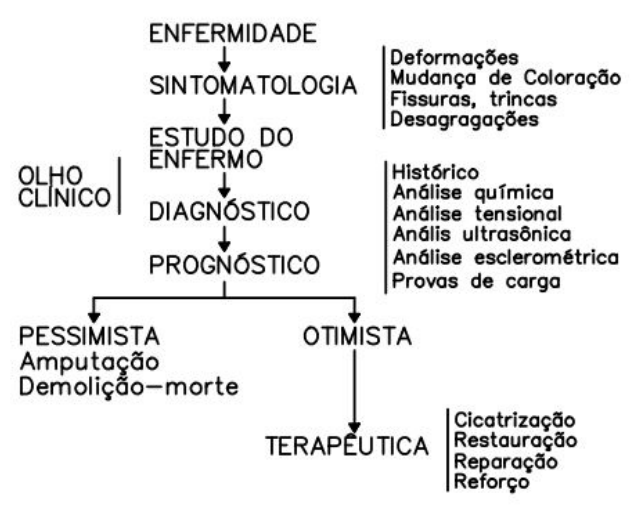

Fonte: Adaptação de Cánovas (1988, p. 12).

Todo material possui uma certa vida útil, e, assim, o desgaste é uma de suas características intrínsecas. Com o avanço constante da tecnologia, entretanto, e o desenvolvimento de novos materiais, torna-se possível resolver anomalias causadas pelo tempo, além de problemas oriundos desde falhas de projeto e execução, até a desqualificação da mão de obra (Goebel, 2018).

A norma de Desempenho das Edificações, NBR 15575 - Edificações habitacionais - Desempenho (ABNT, 2013), destaca que as rotinas de manutenção têm potencial de ampliar a vida útil de uma construção, aumentando consideravelmente o seu desempenho ao longo do tempo.

Quanto mais cedo for realizada a manutenção, mais eficientes serão as correções das manifestações patológicas e menor será o custo envolvido. (Helene; 1993). O mesmo pode ser observado na Lei de Sitter, evidenciado na Figura 2, que expõe que os gastos com manutenção são diretamente proporcionais ao tempo em que dado reparo é realizado, podendo ser até 125 vezes mais oneroso do que quando realizado na fase de projeto.

Figura 2. Lei de Sitter.

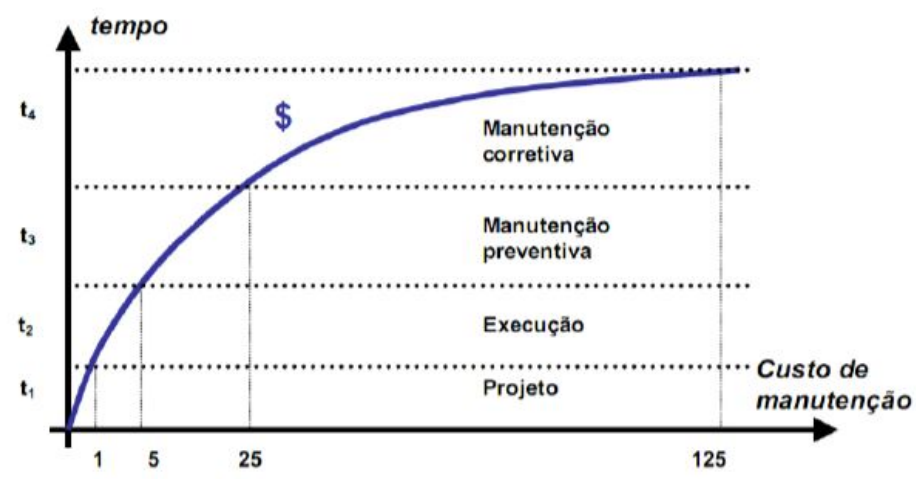

Fonte: Sitter apud (Tutikian e Pacheco 2019).

\subsection{Inspeção}

A Norma de Inspeção Predial Nacional (IBAPE) classifica a inspeção em três níveis, de acordo com a sua complexidade, são eles: nível 1, realizada em construções de pouca complexidade técnica de operação e manutenção dos elementos e sistemas construtivos, normalmente utilizada em edificações com planos de manutenção simples; nível 2, inspeção executada em construções de média dificuldade técnica de manutenção e de operação dos componentes e sistemas construtivos, geralmente aplicada em edificações de vários pavimentos; nível 3 inspeção realizada em 
construções com alta dificuldade técnica de manutenção e operação dos elementos e sistemas construtivos, de padrões superiores e sofisticados, geralmente utilizada em edificações de vários pavimentos ou com sistemas construtivos com automação.

A NBR 16747 - Inspeção predial - Diretrizes, conceitos, terminologia e procedimento (ABNT, 2020) revela que a inspeção predial deve abranger os quesitos de segurança, habitabilidade e sustentabilidade. Já para Gomide (2006), a inspeção é dada como uma visão sistêmica tridimensional que deve ser utilizada no momento de realização de um procedimento dessa natureza em alguma edificação, conforme ilustra a Figura 3.

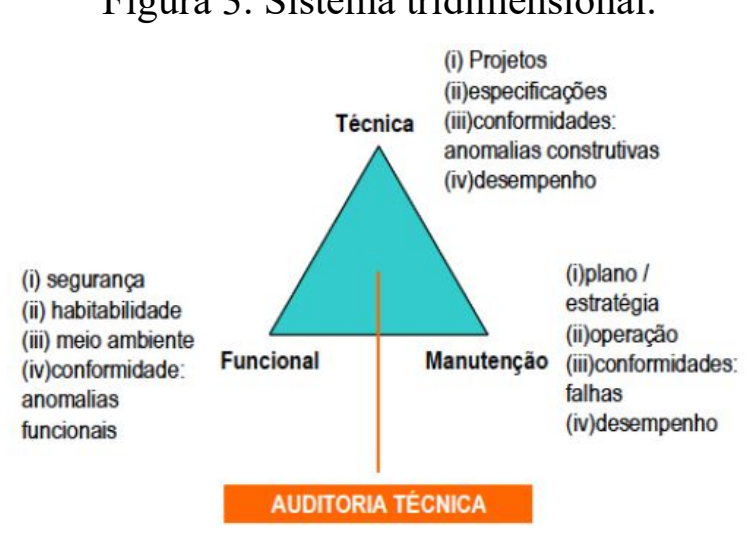

Fonte: Gomide (2006).

Gomide, Neto e Gullo (2009) apresentam como ferramenta para hierarquização, com uso de prognóstico para uma inspeção, a chamada matriz GUT (Gravidade, Urgência e Tendência), representeada na Tabela 2.

Tabela 2. Matriz GUT.

\begin{tabular}{|c|c|c|c|c|}
\hline GRAU & NOTA & GRAVIDADE & URGENCIA & TENDÊECIA \\
\hline MÁXIMO & 10 & Risco à vida dos usuários, colapso de edificação, & $\begin{array}{c}\text { Evolução } \\
\text { imediata }\end{array}$ & Em ocorrência \\
\hline ALTO & 8 & $\begin{array}{c}\text { Risco de ferimentos aos usuários, avaria não } \\
\text { recuperável na edificação, contaminação localizada }\end{array}$ & $\begin{array}{c}\text { Evolução no } \\
\text { curto prazo }\end{array}$ & A ocorrer \\
\hline MÉDIO & 6 & $\begin{array}{c}\text { Insalubridade aos usuários, deterioração elevada da } \\
\text { edificação, desperdício dos recursos naturais }\end{array}$ & $\begin{array}{c}\text { Evolução no } \\
\text { médio prazo }\end{array}$ & $\begin{array}{c}\text { Prognóstico para } \\
\text { breve }\end{array}$ \\
\hline BAIXO & 3 & $\begin{array}{c}\text { Incômodo aos usuários, degradação da edificação, } \\
\text { uso não racional dos recursos naturais }\end{array}$ & $\begin{array}{c}\text { Evolução no } \\
\text { longo prazo }\end{array}$ & $\begin{array}{c}\text { Prognóstico para } \\
\text { adiante }\end{array}$ \\
\hline MÍNIMO & 1 & Depreciação imobiliária & Não evoluirá & Imprevisto \\
\hline
\end{tabular}

Fonte: Adaptação Gomide, Neto e Gullo (2009) apud (Tutikian e Pacheco 2019).

\subsection{Fachada}

A NBR 13755 - Revestimentos cerâmicos de fachadas e paredes externas com utilização de argamassa colante - Projeto, execução, inspeção e aceitação - Procedimento (ABNT, 2017) estabelece alguns requisitos relativos ao uso dos materiais, como componentes para as juntas de movimentação, pastilhas, argamassas e aditivos, considerações de projetos de fachadas, execução dos revestimentos cerâmicos e inspeção. Dentre os aspectos abordados pela norma, pode-se citar: o planejamento dos trabalhos, respeitando, por exemplo, o tempo mínimo de 14 dias da cura do emboço para assentamento das placas cerâmicas; a temperatura ambiente no momento da 
execução, que deve ser entre $+5^{\circ} \mathrm{C}$ e $+40^{\circ}$ e temperatura da base do revestimento entre $+5^{\circ} \mathrm{C} \mathrm{e}+$ $27^{\circ} \mathrm{C}$; o planejamento das juntas de assentamento, de movimentação e de dessolidarização entre outros.

Em um estudo realizado em três obras na cidade de Balneário Camboriú, em Santa Catarina, Luz (2004) encontrou, como manifestações patológicas na fachada, o destacamento das pastilhas, fissuras e manchas nas placas cerâmicas, que se atribuem às falhas de projeto executivo da construção. $\mathrm{O}$ autor associou os problemas encontrados às variações na temperatura da região que favorecem a dilatação e retração do sistema de revestimento cerâmico da fachada - e à presença de sais devido à proximidade das edificações com o mar, o que provavelmente acelerou a degradação dos rejuntes.

\section{MATERIAIS E MÉTODOS}

O intuito deste trabalho é analisar as manifestações patológicas de dois edifícios localizados na beira mar de Capão da Canoa, RS, através de levantamento fotográfico realizado em inspeções nas duas edificações, e verificar a necessidade de reparos ou reforços. Após o levantamento, foi aplicada a matriz GUT buscando uma hierarquização dos danos patológicos.

\subsection{Objeto de estudo}

O Condomínio Edifício Alphaville está localizado na Rua Moema, bairro Centro, na beira mar de Capão da Canoa - RS. Foi construído no ano de 2004, possui 1.696,07 m², divididos em 11 pavimentos, sendo 02 de garagem com 12 box, pavimento tipo com 01 apartamento cada, totalizando 09 unidades. A edificação possui sistema construtivo viga-pilar de concreto armado com blocos de vedação em cerâmica, fachadas revestidas com pastilhas cerâmicas e cobertura em telha fibrocimento. A Figura 4 apresenta o Condomínio Edifício Alphaville.

O segundo prédio em estudo é o Condomínio Edifício The Palace, construído em 2011, situado na mesma quadra do Edifício Alphaville, porém na Rua Tiarajú, que se localiza próxima ao mar. A edificação possui $4.395,64 \mathrm{~m}^{2}$, divididos em 12 pavimentos, com os dois primeiros pavimentos abrigando garagens com 37 box e o restante apartamentos, com 02 unidades em cada andar, e um apartamento por pavimento no décimo primeiro e segundo, totalizando 18 unidades autônomas, e casa de máquinas no alto da edificação. O sistema construtivo utilizado é de viga-pilar de concreto armado com blocos de vedação cerâmicos, fachadas com revestimento cerâmico e cobertura com telhas fibrocimento. A Figura 5 apresenta o Condomínio Edifício The Palace e a Figura 6 ilustra a posição dos dois edifícios em relação ao mar.

Figura 4. Edifício Alphaville.

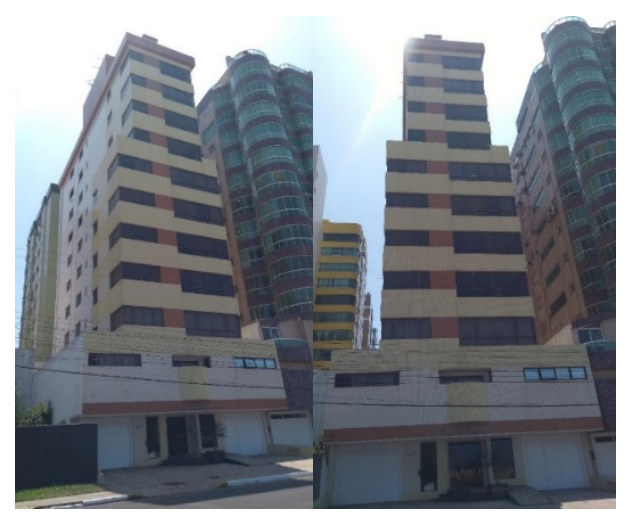

Fonte: Autores. 
Figura 5. Condomínio edifício The Palace.

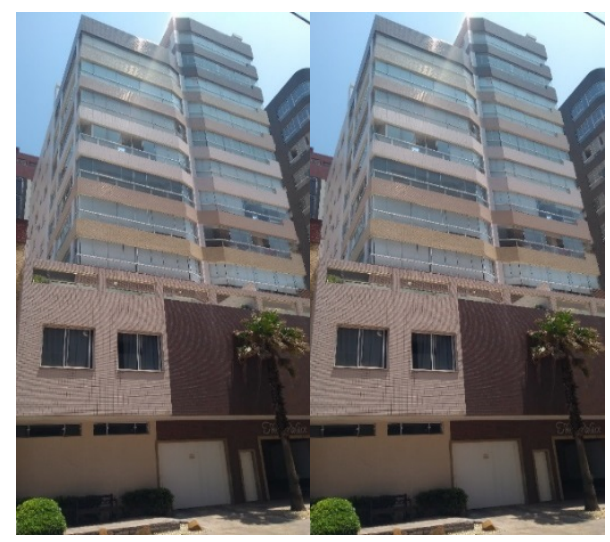

Fonte: Autores.

Figura 6. Localização dos edifícios com relação ao mar.

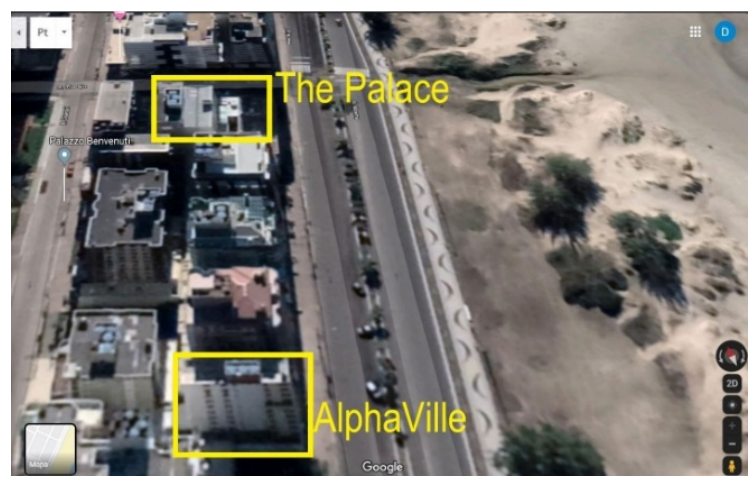

Fonte: Google.

\subsection{Técnica utilizada}

A técnica utilizada para levantamento de dados baseou-se na inspeção no local, com vistoria em todos os espaços - áreas de uso comuns (garagem, corredores, hall de acesso e terraço), áreas privativas (apartamentos) e áreas de serviço (casa de máquinas, reservatórios e telhado). Durante a inspeção, foi realizado o registro fotográfico das manifestações patológicas encontradas e que foram utilizadas na realização dos estudos deste trabalho.

\subsection{Vistorias}

As vistorias foram executadas em datas distintas, sendo que em cada dia foi visitado uma edificação. O Edifício The Palace foi vistoriado no dia 05 de março de 2020, pela manhã, em dia ensolarado com temperatura aproximada de $23^{\circ} \mathrm{C}$. O Edifício Alphaville foi vistoriado no dia 07 de setembro de 2020, também no turno da manhã, com situações climáticas semelhantes às encontradas na vistoria do Edifício The Palace. Ambas as inspeções foram acompanhadas pelos zeladores dos prédios e por alguns condôminos.

\section{RESULTADOS E DISCUSSÃO}

\subsection{The Palace}

A seguir estão listados os danos patológicos encontrados na edificação, de acordo com seu local de ocorrência. 
a) Danos no revestimento

Identificou-se danos que tange à fixação de peças cerâmicas no revestimento da fachada, conforme apresenta a Figura 7a. Ainda em relação ao revestimento, percebeu-se a presença de umidade ascensional, ilustrado na Figura 7b. Os problemas de fixação das peças cerâmicas estão ocorrendo na fachada sul, em toda sua extensão. Como correção, aponta-se a retirada desses revestimentos e para que seja realizada a correta execução dos mesmos. Referente à umidade ascensional descrita na Figura $7 b$, foi percebida no terceiro pavimento, próximo ao terraço.

Figura 7. (a) Danos de fixação de peças cerâmicas; (b) Danos no revestimento causados pela umidade ascensional.

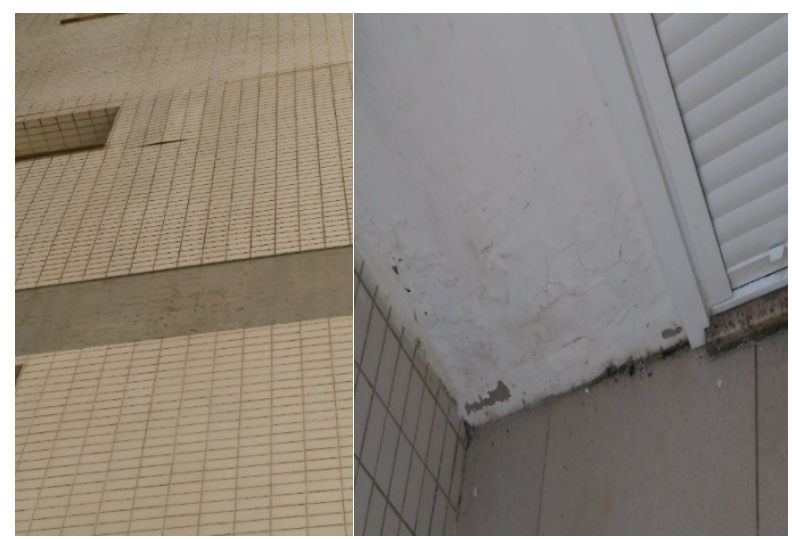

Fonte: Autores.

b) Danos na estrutura

Dentre os danos verificados na estrutura, cabe destacar a corrosão das armaduras no interior dos elementos, exibido na Figura 8a localiza na rampa de subida do estacionamento, a corrosão nas armaduras da laje da garagem próxima à parede - Figura $8 \mathrm{~b}$ - e marcas de corrosão nas armaduras das vigas no segundo pavimento de garagem no centro da viga próximo ao apoio, apresentando sinais de infiltração, conforme mostra a Figura 8c. Ademais, notou-se fissuras em $45^{\circ}$ na região das aberturas do apartamento do zelador, sendo um problema isolado, exemplificado na Figura 8d.

Figura 8. (a) Corrosão das armaduras na rampa do estacionamento; (b) Corrosão na laje; (c) Sinais de umidade e corrosão na viga; (d) Fissura no revestimento cerâmico próximo à abertura.

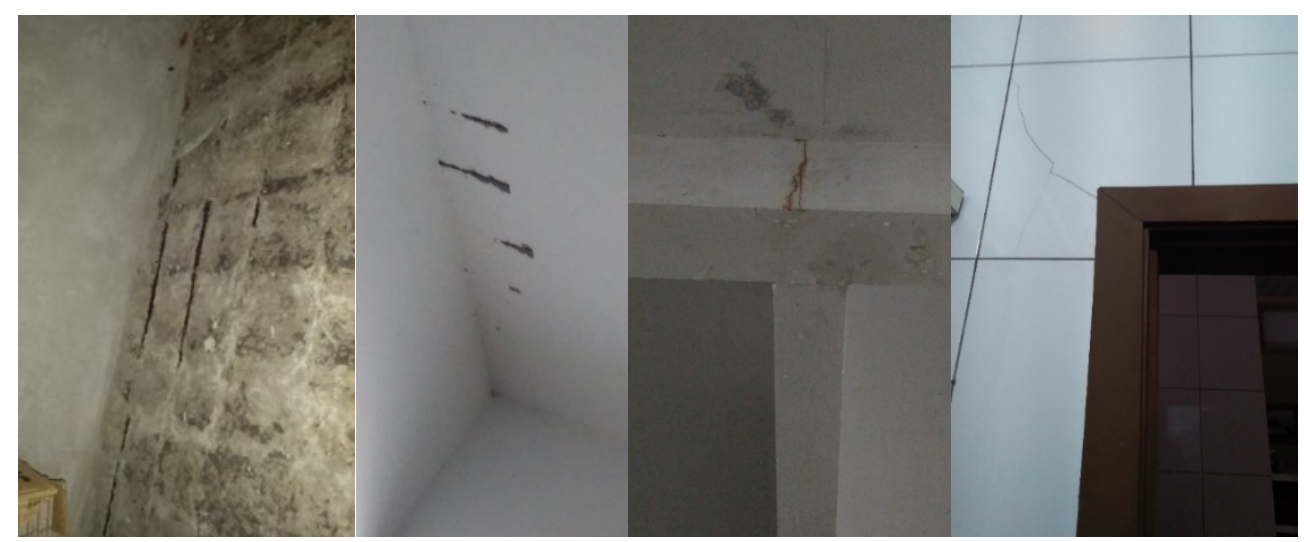

Fonte: Autores. 


\section{c) Presença de fungos}

Diagnosticou-se a presença de fungos na região da central de GLP, conforme a Figura 9a, bem como um pilar com a pintura danificada, no mesmo local (Figura 10b), localizado no pavimento térreo. A coloração amarelada identificada é alusiva à presença de microrganismos, indicando a presença de umidade, condição indispensável para a formação e desenvolvimento de fungos.

Figura 9. (a) Formação de fungos; (b) Pintura do pilar danificada.

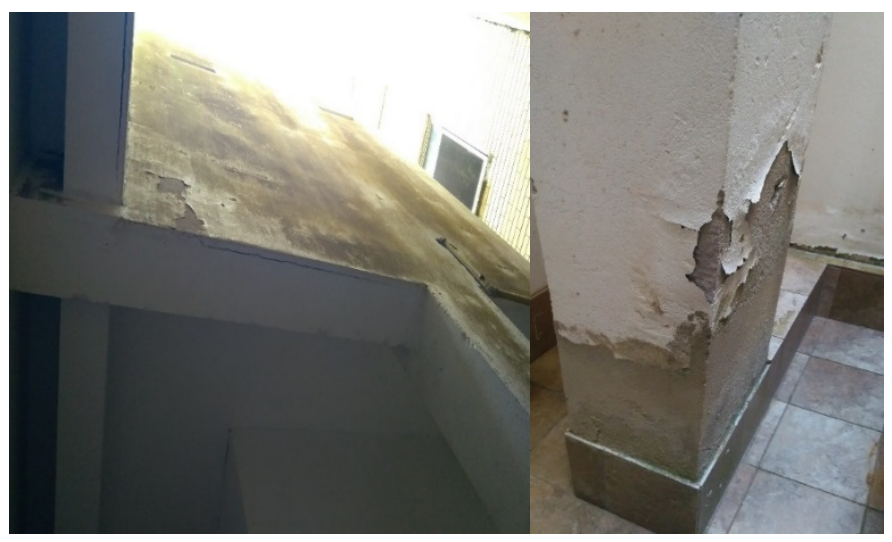

Fonte: Autores.

A Tabela 3 apresenta um resumo dos danos patológicos apresentados na edificação, assim como suas gravidades, urgências e tendências.

Tabela 3. Resumo dos danos patológicos.

\begin{tabular}{|c|c|c|c|c|}
\hline ITEM & GRAVIDADE & URGÊNCIA & TENDÊNCIA & OBSERVAÇÃO \\
\hline $\begin{array}{c}\text { Falha na } \\
\text { aderência das } \\
\text { peças } \\
\text { cerâmicas }\end{array}$ & $\begin{array}{l}\text { Insalubridade aos usuários, } \\
\text { deterioração elevada da } \\
\text { edificação, desperdício dos } \\
\text { recursos naturais }\end{array}$ & $\begin{array}{l}\text { Evolução no } \\
\text { médio prazo }\end{array}$ & $\begin{array}{l}\text { Queda das peças cerâmicas e } \\
\text { penetração de umidade no } \\
\text { local, podendo causar } \\
\text { problemas no restante do } \\
\text { revestimento cerâmico e } \\
\text { argamassado }\end{array}$ & $\begin{array}{l}\text { Deve-se refazer toda a } \\
\text { fachada com todos os } \\
\text { itens necessários }\end{array}$ \\
\hline $\begin{array}{c}\text { Umidade } \\
\text { ascensional }\end{array}$ & $\begin{array}{c}\text { Incômodo aos usuários, } \\
\text { degradação da edificação, uso } \\
\text { não racional dos recursos } \\
\text { naturais }\end{array}$ & $\begin{array}{l}\text { Evolução no } \\
\text { longo prazo }\end{array}$ & $\begin{array}{l}\text { Deterioração do revestimento e } \\
\text { falta de aderência do mesmo, } \\
\text { causando desplacamento }\end{array}$ & $\begin{array}{l}\text { Localizar a origem do } \\
\text { problema, o qual pode } \\
\text { estar sendo causado } \\
\text { por entupimento de } \\
\text { ralo, tendo em vista o } \\
\text { local de ocorrência da } \\
\text { manifestação } \\
\text { patológica, o terraço, e } \\
\text { refazer o revestimento } \\
\text { e a pintura }\end{array}$ \\
\hline $\begin{array}{c}\text { Corrosão das } \\
\text { armaduras }\end{array}$ & $\begin{array}{l}\text { Insalubridade aos usuários, } \\
\text { deterioração elevada da } \\
\text { edificação, desperdício dos } \\
\text { recursos naturais }\end{array}$ & $\begin{array}{l}\text { Evolução no } \\
\text { médio prazo }\end{array}$ & $\begin{array}{l}\text { Aumento da corrosão das } \\
\text { armaduras, desplacamento do } \\
\text { concreto, podendo levar ao } \\
\text { colapso dos elementos }\end{array}$ & $\begin{array}{l}\text { Identificar a origem da } \\
\text { corrosão, que pode } \\
\text { estar sendo causada } \\
\text { por infiltração, então } \\
\text { deve-se estancar a } \\
\text { mesma e assim tratar } \\
\text { as armaduras e, se } \\
\text { necessário, refazer a } \\
\text { concretagem do } \\
\text { elemento com novo } \\
\text { elemento }\end{array}$ \\
\hline
\end{tabular}




\begin{tabular}{|c|c|c|c|c|}
\hline $\begin{array}{c}\text { Fissuração na } \\
\text { região das } \\
\text { aberturas }\end{array}$ & $\begin{array}{c}\text { Incômodo aos usuários, } \\
\text { degradação da edificação, uso } \\
\text { não racional dos recursos } \\
\text { naturais }\end{array}$ & $\begin{array}{c}\text { Evolução no } \\
\text { longo prazo }\end{array}$ & $\begin{array}{c}\text { Aumento da fissura, problemas } \\
\text { no funcionamento das } \\
\text { esquadrias, desplacamento do } \\
\text { revestimento cerâmico }\end{array}$ & $\begin{array}{c}\text { Deve-se monitorar o } \\
\text { tamanho da fissura e, } \\
\text { se necessário, realizar } \\
\text { reparo }\end{array}$ \\
\hline $\begin{array}{c}\text { Presença de } \\
\text { fungos }\end{array}$ & $\begin{array}{c}\text { Insalubridade aos usuários, } \\
\text { deterioração elevada da } \\
\text { edificação, desperdício dos } \\
\text { recursos naturais }\end{array}$ & $\begin{array}{c}\text { Evolução no } \\
\text { longo prazo }\end{array}$ & $\begin{array}{c}\text { Deterioração de maior parte do } \\
\text { revestimento, podendo } \\
\text { ocasionar seu colapso }\end{array}$ & $\begin{array}{c}\text { Deve-se realizar a } \\
\text { lavagem do local e } \\
\text { refazer a pintura }\end{array}$ \\
\hline $\begin{array}{c}\text { Dano na } \\
\text { pintura do } \\
\text { pilar }\end{array}$ & $\begin{array}{c}\text { Incômodo aos usuários, } \\
\text { degradação da edificação, uso } \\
\text { não racional dos recursos } \\
\text { naturais }\end{array}$ & $\begin{array}{c}\text { Evolução no } \\
\text { longo prazo }\end{array}$ & $\begin{array}{c}\text { Presença de umidade e queda } \\
\text { do revestimento argamassado }\end{array}$ & $\begin{array}{c}\text { Localizar a presença de } \\
\text { umidade no local, } \\
\text { verificando se há } \\
\text { acúmulo de água que } \\
\text { possa estar danificando } \\
\text { a pintura, e refazer a } \\
\text { mesma }\end{array}$ \\
\hline
\end{tabular}

\subsection{Alphaville}

A seguir, estão listados os danos patológicos encontrados na edificação, de acordo com seu local de ocorrência.

\section{a) Danos no revestimento}

Em relação aos revestimentos, foram diagnosticados danos patológicos nas proximidades das aberturas, conforme mostra Figura 10a, e nocividades oriundos da umidade ascensional na região da sacada, ilustrado na Figura 10b, ambas localizadas no sétimo pavimento. Trata-se de um problema isolado de apenas um apartamento no referido pavimento. Como a fachada está em bom estado neste local, acredita-se que o problema exposto na Figura 10a seja ocasionado pela má execução da vedação entre a abertura e a alvenaria. Alusivo à Figura 10b, a manifestação patológica apresentada pode ter como causa infiltrações na interface da laje com a alvenaria.

Figura 10. (a) Dano no revestimento próximo à abertura; (b) Problema por umidade ascensional no revestimento da sacada.

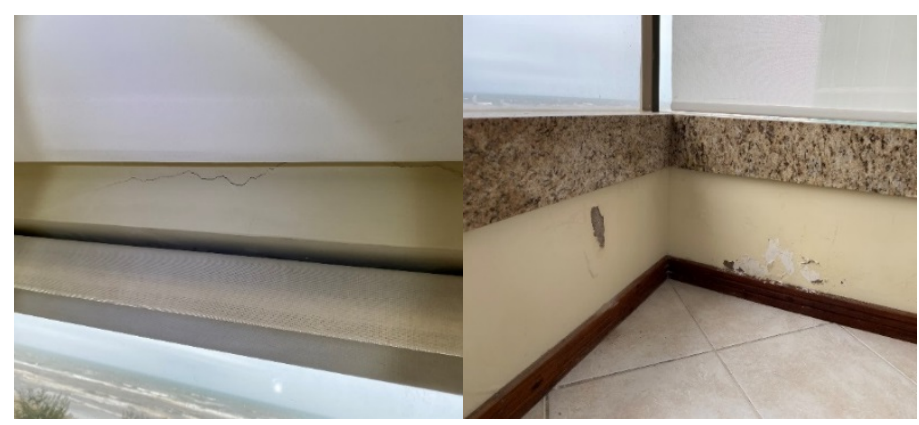

Fonte: Autores.

b) Danos na cobertura

No telhado, identificou-se problemas na impermeabilização e na calha (Figura 11a), além de proliferação de fungos próximo à edificação vizinha, conforme a Figura 11b. 
Figura 11. (a) Falha na calha e impermeabilização; (b) Formação de fungos.

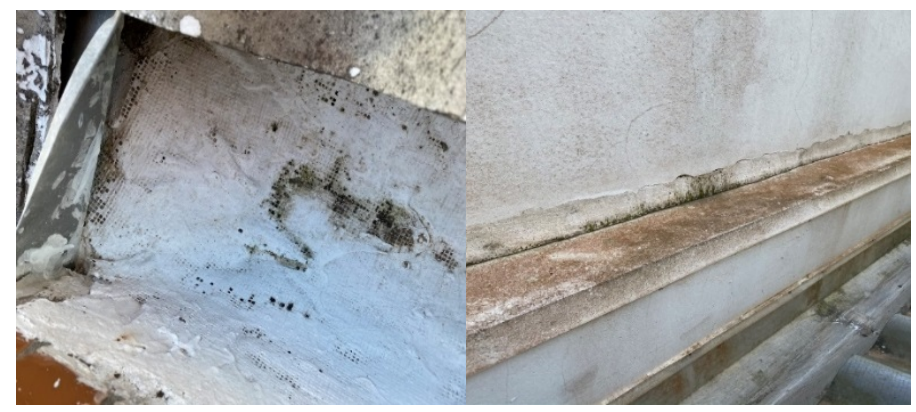

Fonte: Autores.

c) Corrosão longitudinal

A Figura 12 expõe uma fissura no revestimento, que pode estar associada à formação de corrosão na armadura longitudinal na cobertura da edificação.

Figura 12. Fissura no revestimento.

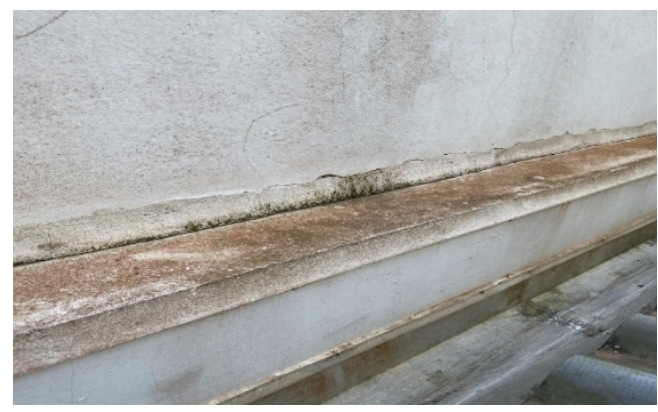

Fonte: Autores.

d) Umidade ascensional

Em um apartamento, localizado no sexto pavimento, notou-se a presença de umidade ascensional em paredes internas, como exemplifica as Figuras 13 (a) e (b). Essas manifestações patológicas podem ser causadas por infiltrações na interface da laje com a alvenaria, pois os locais não estão próximos nem de shafts hidráulicos, nem de lavabos e banheiros. Além disso, trata-se de aspectos isolados apenas no referido andar.

Figura 13. (a) Pintura danificada; (b) Dano no revestimento.

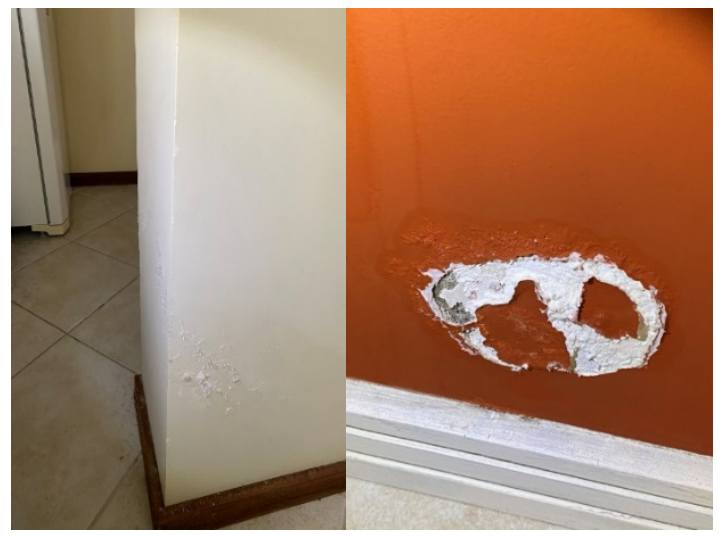

Fonte: Autores. 
A Tabela 4 apresenta um resumo dos danos patológicos detectados na edificação, informando suas gravidades, urgências e tendências.

Tabela 4. Resumo dos danos patológicos.

\begin{tabular}{|c|c|c|c|c|}
\hline ITEM & GRAVIDADE & URGÊNCIA & TENDÊNCIA & OBSERVAÇÃO \\
\hline $\begin{array}{l}\text { Umidade } \\
\text { ascensional }\end{array}$ & $\begin{array}{l}\text { Incômodo aos usuários, } \\
\text { degradação da edificação, } \\
\text { uso não racional dos } \\
\text { recursos naturais }\end{array}$ & $\begin{array}{l}\text { Evolução no } \\
\text { longo prazo }\end{array}$ & $\begin{array}{c}\text { Deterioração e falta de } \\
\text { aderência do revestimento, } \\
\text { causando desplacamento }\end{array}$ & $\begin{array}{l}\text { Localizar a origem do } \\
\text { problema, investigando a } \\
\text { presença de umidade no } \\
\text { local, que pode estar } \\
\text { danificando o revestimento e } \\
\text { refazer o mesmo e a pintura }\end{array}$ \\
\hline $\begin{array}{l}\text { Fissuração na } \\
\text { região das } \\
\text { aberturas }\end{array}$ & $\begin{array}{l}\text { Incômodo aos usuários, } \\
\text { degradação da edificação, } \\
\text { uso não racional dos } \\
\text { recursos naturais }\end{array}$ & $\begin{array}{l}\text { Evolução no } \\
\text { longo prazo }\end{array}$ & $\begin{array}{l}\text { Aumento da fissura, } \\
\text { problemas no funcionamento } \\
\text { das esquadrias, queda do } \\
\text { revestimento cerâmico }\end{array}$ & $\begin{array}{c}\text { Deve-se monitorar o } \\
\text { tamanho da fissura e, se } \\
\text { necessário, realizar o reparo }\end{array}$ \\
\hline $\begin{array}{l}\text { Presença de } \\
\text { fungos }\end{array}$ & $\begin{array}{l}\text { Insalubridade aos usuários, } \\
\text { deterioração elevada da } \\
\text { edificação, desperdício dos } \\
\text { recursos naturais } \\
\end{array}$ & $\begin{array}{l}\text { Evolução no } \\
\text { longo prazo }\end{array}$ & $\begin{array}{c}\text { Deterioração de maior parte } \\
\text { do revestimento, ocasionando } \\
\text { seu colapso }\end{array}$ & $\begin{array}{l}\text { Deve-se realizar a lavagem } \\
\text { do local e refazer a pintura }\end{array}$ \\
\hline $\begin{array}{c}\text { Calha e } \\
\text { impermeabili } \\
\text { zação } \\
\text { danificada } \\
\end{array}$ & $\begin{array}{l}\text { Incômodo aos usuários, } \\
\text { degradação da edificação, } \\
\text { uso não racional dos } \\
\text { recursos naturais }\end{array}$ & $\begin{array}{l}\text { Evolução no } \\
\text { longo prazo }\end{array}$ & $\begin{array}{c}\text { Entupimento da calha, } \\
\text { transbordo e possível } \\
\text { infiltração na laje de } \\
\text { cobertura }\end{array}$ & $\begin{array}{c}\text { Localizar a presença de } \\
\text { umidade no local e refazer a } \\
\text { impermeabilização }\end{array}$ \\
\hline $\begin{array}{l}\text { Corrosão das } \\
\text { armaduras }\end{array}$ & $\begin{array}{l}\text { Insalubridade aos usuários, } \\
\text { deterioração elevada da } \\
\text { edificação, desperdício dos } \\
\text { recursos naturais }\end{array}$ & $\begin{array}{l}\text { Evolução no } \\
\text { médio prazo }\end{array}$ & $\begin{array}{l}\text { Aumento da corrosão das } \\
\text { armaduras, desplacamento do } \\
\text { concreto, podendo acarretar } \\
\text { no colapso dos elementos }\end{array}$ & $\begin{array}{l}\text { Identificar e tratar a origem } \\
\text { da corrosão e, se necessário, } \\
\text { concretar novamente o } \\
\text { elemento com nova } \\
\text { armadura }\end{array}$ \\
\hline
\end{tabular}

\subsection{Análise dos resultados}

Realizada a análise, percebe-se que ambas edificações possuem avarias que se caracterizadas por evolução de médio e de longo prazo.

Na edificação The Palace salienta-se para o risco de desplacamento e queda de peças cerâmicas, podendo colocar em risco, além dos próprios usuários da construção, os indivíduos que se deslocam em seu entorno. Outro dano notável e que demanda certa urgência de intervenção é a corrosão das armaduras, visto que, por localizar-se próximo à orla marinha, há elevado risco de evolução desse dano em caráter progressivo, com aumento da velocidade do processo corrosivo, podendo culminar na perda considerável de seção transversal das armaduras, com potencial de abalar a capacidade estrutural da edificação. Os demais malefícios diagnosticados também causam impactos na edificação, contudo em menor intensidade e à longo prazo, dentre os quais pode-se citar o surgimento de fungos emboloradores e a umidade ascensional.

Em relação à edificação Alphaville, nota-se, mais uma vez, a agressividade do local imposta pela presença de cloretos, evidenciada na corrosão das armaduras, cuja correção deve ser uma prioridade na intervenção do edifício. Percebe-se, assim como no The Palace, a problemática da umidade ascensional e a presença de fungos, degenerações passíveis de ocorrência e características da elevada umidade, circunstância identificada em ambas construções investigadas.

Constata-se, entre as semelhanças encontradas em abas as edificações, a falta de manutenção preventiva e de rotinas de inspeções, visto que determinadas manifestações patológicas observadas - como umidade ascensional e presença de fungos - poderiam ser sanadas e prevenidas previamente, se corretamente realizadas as práticas de conservação. No edifício Alphaville, também, nota-se a falta de limpeza na calha da cobertura, ressaltando a falta de manutenção na edificação. 
Os malefícios encontrados nas duas construções assemelham-se e podem ser justificados em função das suas localizações, uma vez que ambas possuem vicinalidade com o mar. Outrossim, os sistemas construtivos são análogos, o que reforça a ideia de semelhança entre as manifestações patológicas encontradas.

\section{CONCLUSÃO}

Essa pesquisa realizada em edifícios situados em município litorâneo destaca a importância da execução correta das rotinas de inspeção e manutenção nas edificações, visto que esses hábitos, além de solucionar, também contribuem para a profilaxia de diversas manifestações patológicas que podem se desenvolver ao longo do tempo nas construções. Evidencia-se, ainda, o potencial efetivamente agressivo que o meio marinho exerce sobre as estruturas.

Em relação aos danos patológicos das edificações analisadas, pode-se afirmar que, em ambas, as rotinas de inspeção e manutenção preventiva foram falhas ou até inexistentes, pois, se executadas corretamente, poderiam tem solucionado ou evitado o desenvolvimento das manifestações patológicas identificadas. Como aspectos que careçam de intervenção imediata, pode-se destacar a corrosão das armaduras, que podem causar danos estruturais em ambos os prédios, o descolamento das peças cerâmicas das fachadas, que apresentam sérios riscos aos usuários e indivíduos que transitam nos arredores, e a presença de umidade ascensional nos revestimentos, que pode levar ao seu desplacamento e queda.

Em virtude dos malefícios encontrados serem, de certa forma, passíveis de ocorrência tendo em vista a localização e idade das construções, conclui-se que os resultados obtidos após vistoria e análise das edificações está dentro do esperado.

\section{REFERÊNCIAS}

Alves, Amara Midiã Correia. (2007), "Contribuição à análise da perspectiva de vida útil de estruturas em concreto face ao teor de cloreto registrado em Maceó-AL". 2007. Dissertação (Mestrado em Engenharia Civil) - Programa de Pós-Graduação em Engenharia Civil, Universidade Federal de Alagoas, Maceió.

Associação Brasileira de Normas Técnicas. (2013). NBR 15.575-1: Edificações Habitacionais: desempenho, parte 1, requisitos gerais. Rio de Janeiro.

Associação Brasileira de Normas Técnicas. (2020). NBR 16747: Inspeção predial - Diretrizes, conceitos, terminologia e procedimento. Rio de Janeiro.

Associação Brasileira de Normas Técnicas. (2014). NBR 6118: Projeto de estruturas de concreto - Procedimentos. Rio de Janeiro.

Associação Brasileira de Normas Técnicas. (2017). NBR 13.755: Revestimento cerâmicos de fachadas de paredes externas com utilização de argamassa colante. Rio de Janeiro.

Cánovas, Manuel Fernández. (1988), “Patologia e terapia do concreto armado”. São Paulo: Pini.

Goebel, Claudio da Silva de. (2018), "Levantamento das Principais Manifestações Patológicas nos Prédios das Escolas Municipais da Cidade de Pelotas”, Dissertação (mestrado) - Programa de Pós-Graduação em Engenharia Civil, Universidade do Vale do Rio dos Sinos, São Leopoldo, Rio Grande do Sul, p. 121. 
Gomide, T. L. (2016), “Engenharia e Diagnóstico na Reabilitação de Edificações”. 115 slides.

Gomide, T. L.; Neto, J. C. P. F.; Gullo, M. A. (2009), "Normas técnicas para engenharia diagnósticas em edificações". 1. ed. São Paulo: Pini.

Helene, P. (1993), “Contribuição ao estudo da corrosão em armaduras de concreto armado”. São Paulo.

Helene, P. (1986), “Corrosão em Armaduras para Concreto Armado”. São Paulo: PINI.

Instituto Brasileiro de Avaliações e Perícias de Engenharia. (2012). IBAPE: Norma de Inspeção Predial Nacional. São Paulo.

Lima, Maryangela Geimba de. (2011), Açõs do Meio Ambiente sobre as Estruturas de Concreto. In: ISAIA, Geraldo Cechella (ed.). "Concreto: Ciência e Tecnologia". 1. ed. São Paulo: IBRACON. v. 1. cap. 22. p. 733-772.

Luz, Marcos de Almeida (2004), "Manifestações Patológicas em Revestimentos Cerâmicos de Fachada em Três Estudos de Caso na Cidade de Balneário Camboriú”, Dissertação (Curso de Pós-graduação em Arquitetura e Urbanismo da Universidade Federal de Santa Catarina para a obtenção do título de Mestre em Arquitetura) - Área de concentração: Tecnologia do Ambiente Construído - Sistemas Construtivos, Florianópolis, Santa Catarina. p. 172.

Mehta, P. Kumar; Monteiro, Paulo J. M. (2014), "Concreto: microestrutura, propriedades e materiais". 2. ed. São Paulo: PINI.

Pacheco, F. (2016), "Investigação da relação entre os parâmetros de projeto das estruturas de concreto armado visando à durabilidade”, Dissertação (mestrado) - Programa de Pós-Graduação em Engenharia Civil, Universidade do Vale do Rio dos Sinos, São Leopoldo, Rio Grande do Sul. p. 185.

Pacheco, F.; Tutikian, B. (2019). “Durabilidade das Estruturas de Concreto Armado”. Notas de aula - Programa de Pós-Graduação em Engenharia Civil, Universidade do Vale do Rio dos Sinos, São Leopoldo, Rio Grande do Sul. p. 259.

Pedroso, Fábio Luiz. (2009), “Concreto: as origens e a evolução do material construtivo mais usado pelo homem”. Revista Concreto e Construções. IBRACON, n. 53, p. 14-19.

Rebmann, Markus Samuel. (2011), "Durabilidade de concretos estruturais com baixo consumo de cimento Portland e alta resistência”. Dissertação (Mestrado em Engenharia Civil) - Escola de Engenharia de São Carlos da Universidade de São Paulo, São Carlos.

Ribeiro, Daniel Véras. et al. (2018), “Corrosão e Degradação em Estruturas de Concreto: Teoria, controle e técnicas de análise e intervenção”. 2. ed. Rio de Janeiro: Elsevier.

Sangadji, Senot. (2017), "Porus Network ConcretE: a bio-inspired building component to make cocnrete srtuctures self-healing”. Tese (Doutorado em Engenharia Civil) - Institut Teknologi Bandung, Indonésia.

Silva, J. Mendes da. (2002), “Alvenarias não estruturais patológicas e estratégicas de reabilitação”. Seminário sobre Paredes de Alvenaria, Universidade de Coimbra, Porto, Portugal. 